Research Article

\title{
Nonlinear Stress Analysis of Flexible Pile Composite Foundation by Energy Method
}

\author{
Youping Wu $(\mathbb{D}$, Liangming Fu, Wenping Wu, Yuanyuan Cao, and Xuanyang Zhou \\ PowerChina Zhongnan Engineering Co. Ltd., Changsha 410014, China \\ Correspondence should be addressed to Youping Wu; wwuyn@163.com
}

Received 26 April 2018; Accepted 4 July 2018; Published 19 July 2018

Academic Editor: Md Mainul Islam

Copyright (C) 2018 Youping Wu et al. This is an open access article distributed under the Creative Commons Attribution License, which permits unrestricted use, distribution, and reproduction in any medium, provided the original work is properly cited.

To calculate the stress of cement-soil pile (flexible pile) in composite foundation accurately and overcome the defective preposition that the pile and the soil are elastic, the nonlinear analysis and calculation of pile-soil stress by adopting the energy method are performed. First, on the basis of the universally adopted load transfer method, it is assumed that the friction and the relative displacement of the pile shaft conform with the elastic-plastic relationship. Then, the modified Cam-clay model is introduced to calculate the compressive amount of soil around the pile. Further, the stress and strain characteristics curve of the flexible pile is used to calculate the compression of the pile, deducing the energy equation of the pile and soil around the pile, establishing the total potential energy expression of the flexible pile composite foundation, and the load sharing value and the corresponding stress value of the pile-soil are obtained based on the minimum potential energy principle. Finally, this method is verified by indoor laboratory model test and the reported case. The results show that the calculated solutions are in agreement with the measurements; therefore, the calculation method is reasonable.

\section{Introduction}

Cement-soil piles [1] or cement-soil pile composite foundations [2] have been used in ground treatment. In the design of composite foundation, pile-soil stress ratio constitutes an important parameter for the design of composite foundation. In the early stage, the pile-soil stress ratio of the cement-soil pile composite foundation stemmed mainly from field load test data [3,4]. Baumann and Bauer [5] put forward an empirical formula taking deformation modulus, displacement ratio, and side pressure coefficient into consideration through the analysis of the deformation of gravel pile and soil around the pile as well as the soil pressure. Simplified methods were adopted to analyse the stress of the piles proposed by Poulos and Davis [6]. Due to the deformation of mixing piles composite foundation and the distinctive distribution of soil pressure, Duan [7] and Kitazume and Terashi [8] found that the pile-soil stress ratio $n$ is mainly related to the ratio of pile-soil modulus. Song et al. [9] held the idea that the stress ratio was proportional to the $1 / 2$ of pile-soil modulus ratio, and the comprehensive empirical parameter $\alpha$ is introduced to reflect the nature of soil and load, and then the formula for calculating the stress ratio of mixing pile was proposed. Ishikura et al. $[10,11]$ by using the average skin friction deduced the average stress distribution ratio after consolidation. The above formula was a fitting formula based on measured data. Afterwards, many scholars set up equations on the basis of the theory of pile-soil interaction. Alamgir et al. [12] proposed a onedimensional displacement model that did not consider radial displacement and deduced an analytic calculation formula of the pile shaft stress, pile skin friction, and settlement of the reinforcement area. Based on the above study, Liu and Zhang [13] obtained an analytical solution with the two-dimensional displacement mode considering the radial displacement. However, these studies failed to consider the relative displacement between the pile and soil. Lv et al. [14] and $\mathrm{Yu}$ et al. [15] assumed that the pile-soil interface had relative displacement, and the settlement difference between the soil and pile at the same depth, modifying Alamgir displacement model, and deducing the analytic solution of the working characteristics of the composite foundation 
under the flexible foundation. In 2011, Yu et al. [16] improved on the assumption of the linear distribution of the side friction of a pile along the depth, using the nonlinear distribution of skin friction of the pile along the depth. The paper [5-16] performed a study of the pile and soil, assuming them to be an elastic material, which was different from the nonlinearity of materials in practice. Therefore, Qin et al. [17] adopted the load-settlement hyperbolic model to analyse the pile-soil stress ratio. Huang and Huang [18] and Zheng and Huang [19] used the bilinear load transfer function and hyperbolic function to represent the pile and soil load-settlement curve, respectively, and deduced an analytical formula of the pile-soil stress ratio. In addition, Low et al. [20], $\mathrm{Hu}$ [21], and Zhou et al. [22] deduced a formula for pile-soil stress of composite foundations by analysis of the stress that the effect of soil arching exerts on the pile top. Zhao et al. [23], Yang et al. [24], and Zhao et al. [25] performed a comprehensive analysis of the effect of a reinforced cushion on the pile-soil stress ratio and derived the calculation of the pile-soil stress ratio and settlement of the pile-net composite foundation. Currently, the main problem in the study of pile-soil stress calculations is that the pile or soil is assumed to be an elastomer [5-16], which is obviously not realistic. In this paper, it is assumed that the soil satisfies the modified Cam-clay model, the constitutive behaviour of the cement-soil pile is introduced to describe the nonlinearity of the pile, and an equation is established to perform the calculation of pile-soil stress based on the fact that skin friction of the pile shaft and the relative displacement conforms with elastic-plastic relations.

The energy method based on the principle of energy conservation can be used to analyse the displacement, deformation, and internal forces of deformable solids. Shen et al. [26] used the minimum potential energy principle to analyse the interaction between the pile group and the pile cap. Zheng et al. [27] deduced the analytical solution of the composite modulus of the composite foundation by applying the parametric variational principle. Liu et al. [28] established the energy balance equation of the pile shaft and obtained the settlement of the foundation pile by adopting the pile skin resistance and end resistance model which explains the energy transfer process between the pile shaft and soil. Yang [29] and Zhao et al. [30] used the energy method to solve for the foundation pile axial force and displacement to obtain a calculation method for the settlement of elevated caps pile foundations. At present, the energy method is confined to the pile foundation calculation that does not take the load sharing of the soil into consideration. It does not work in the calculation of composite foundation as well. Therefore, this paper attempts to establish a new energy method analysis model for the stress calculation of composite foundation based on energy conservation law. The paper deduced the formula of the energy equation of the reinforced pile shaft and the soil based on the proper simplification of the model, and the total potential energy expression of the flexible pile composite foundation is established. It also adopts the minimum potential energy principle to obtain the load sharing ratio of the pile and soil, and the stress of the pile and the soil are calculated, thus providing a new calculation method for the stress calculation of the composite foundation.

\section{Stress Calculation of Composite Foundation}

2.1. Pile-Soil Interaction Model. In the composite foundation, the cushion adjusts the pile-soil stress differently with the load, which eventually stabilises. To analyse the compression of the pile and soil in the reinforced area, the paper selects the centre pile in the composite foundation (as shown in Figure 1) as the object of analysis. Suppose that the analysis unit under the load is $p$, the central pile shares the load for the pile $p_{p}$ and that the soil shares the load $p_{s}$. In Figure $1, s_{\mathrm{p} 0}$ is the displacement of the pile top. $s_{\mathrm{b}}$ is the displacement of the pile end. $s_{\mathrm{s} 0}$ is the displacement of the soil between the piles. $\tau_{i}$ is the pile skin friction. The pile area is $A_{\mathrm{p}}$, and the calculated area of soil around the pile is $A_{\mathrm{s}}$. The pile diameter is $d$. Therefore,

$$
\begin{aligned}
p & =p_{\mathrm{p}}+p_{\mathrm{s}}, \\
\sigma_{i} & =\sigma_{i-1}-\tau_{i} \pi d d z+\rho_{\mathrm{p}} g A_{\mathrm{g}} d z .
\end{aligned}
$$

2.2. Calculation Model of Pile Side Friction. The pile skin friction is usually related to the relative displacement between the pile and soil. It is generally considered that the pile skin friction and the relative displacement between the pile and soil accord with the elastic-plastic mathematics model [25]. That is, when the relative displacement between the pile and soil reaches a certain critical value, pile skin friction will reach the maximum (as shown in Figure 2). The skin friction of each pile section along the depth is

$$
\begin{array}{ll}
\tau_{i}=c_{\mathrm{s}} \cdot s_{i}, & s_{i}<s_{\mathrm{u}}, \\
\tau_{i}=\tau_{\mathrm{u}}, & s_{i} \geq s_{\mathrm{u}},
\end{array}
$$

where $s_{i}$ is the relative displacement of the pile shaft $i$, $s_{i}=s_{\mathrm{p} i}-s_{\mathrm{s} i} ; \tau_{\mathrm{u}}$ is the ultimate friction resistance of the layer $i$ of soil; $s_{\mathrm{u}}$ is the minimum displacement of the pile-soil when the layer $i$ achieves ultimate friction $\tau_{\mathrm{u}}$; and $c_{\mathrm{s}}$ is the friction resistance transmission coefficient of the layer $i$, $c_{\mathrm{s}}=\left(\tau_{\mathrm{u}} / s_{\mathrm{u}}\right)$.

2.3. Calculation Model of Pile Bottom Resistance. As for the undamaged pile after the pile bottom pierced the underlying stratum, the relationship between the pile bottom resistance and displacement can be simulated by the double fold line model [31], as shown in Figure 3.

The pile bottom resistance can be expressed as

$$
\begin{array}{ll}
\tau_{\mathrm{b}}=k_{1} \cdot s_{\mathrm{b}}, & s_{\mathrm{b}}<s_{\mathrm{bu}}, \\
\tau_{\mathrm{b}}=k_{1} \cdot s_{\mathrm{bu}}+k_{2} \cdot\left(s_{\mathrm{b}}-s_{\mathrm{bu}}\right), & s_{\mathrm{b}} \geq s_{\mathrm{bu}},
\end{array}
$$

where $s_{\mathrm{b}}$ is the displacement of the pile bottom; $k_{1}$ is the slope of the first straight line; $s_{\mathrm{bu}}$ is the displacement of the first line corresponding to the limit displacement value, usually $(0.5 \% \sim 2.5 \%) d, \mathrm{~mm} ; k_{2}$ is the slope of the second 


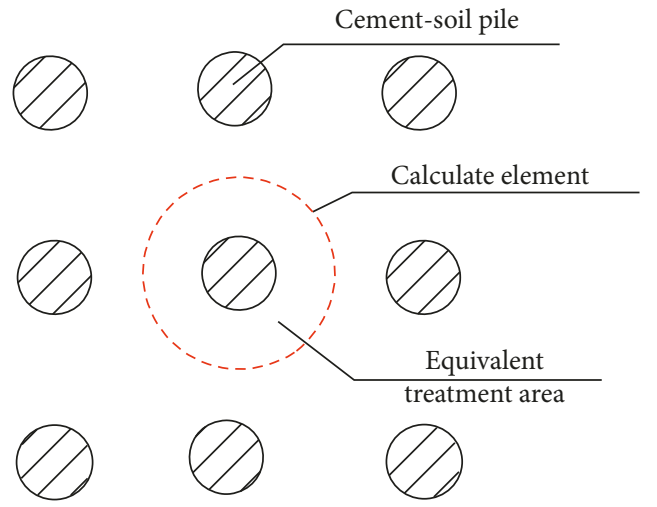

(a) Typical unit
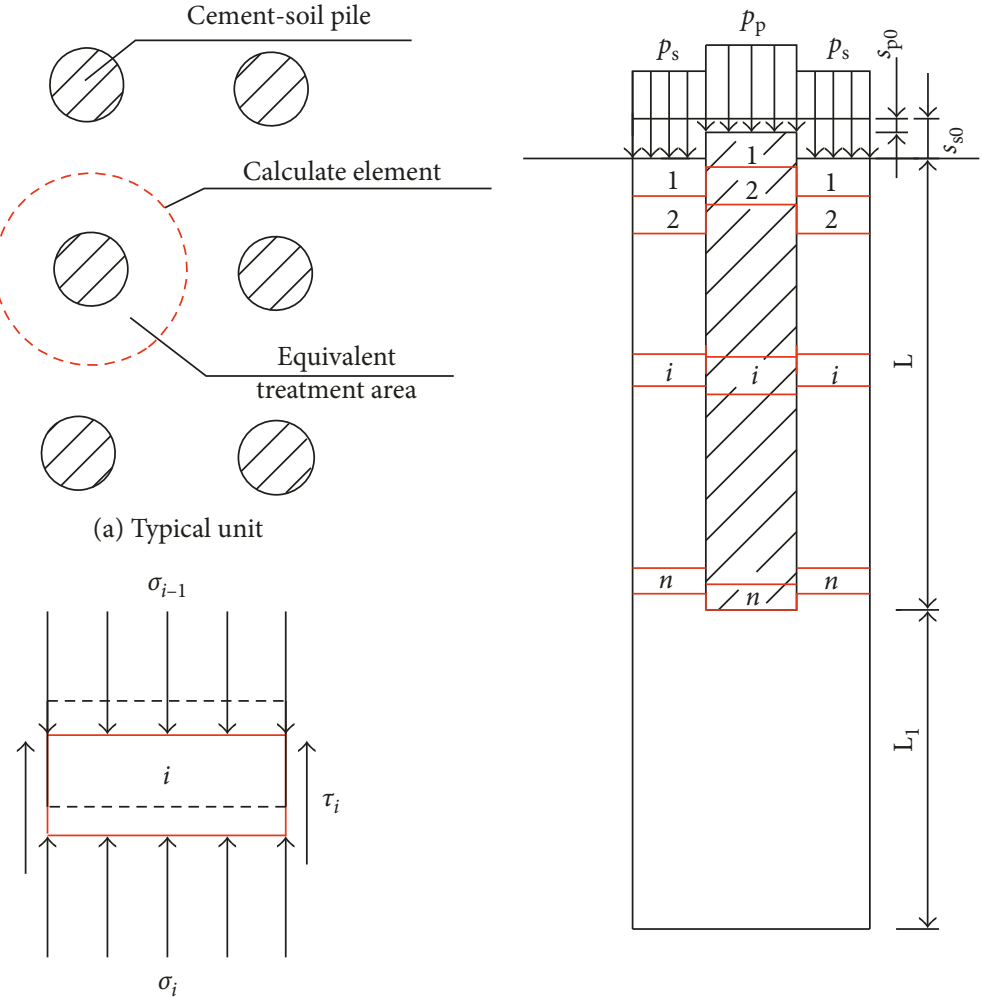

(b) Balance of vertical loading on pile

(c) Element of pile and soil

Figure 1: Schematic diagram of pile-soil interaction.

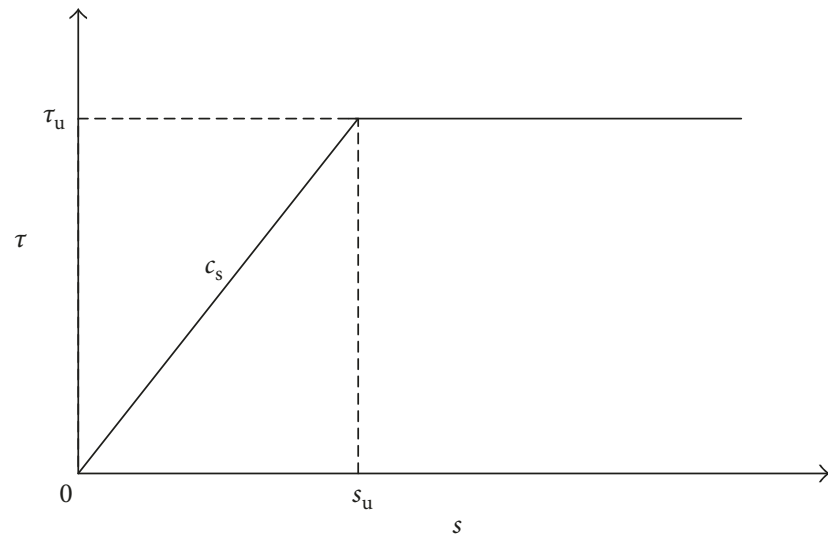

FIGURE 2: Calculation model of pile side friction.

line; and $k_{1}$ can be calculated according to the following formula [32]:

$$
k_{1}=\frac{4 G_{\mathrm{b}}}{\pi r_{0}\left(1-v_{\mathrm{b}}\right)},
$$

where $G_{\mathrm{b}}$ and $v_{\mathrm{b}}$ are the shear modulus and Poisson's ratio of pile bottom soil, respectively, and $k_{2}$ can be obtained by inverse analysis of the load-sedimentation curve in field tests. It can be calculated by the following formula [33]:

$$
k_{2}=\frac{\Delta P_{\mathrm{t}}}{A_{\mathrm{p}}\left(\Delta S_{\mathrm{t}}-\left(\Delta P_{\mathrm{t}} L / E_{\mathrm{p}} A_{\mathrm{p}}\right)\right)},
$$

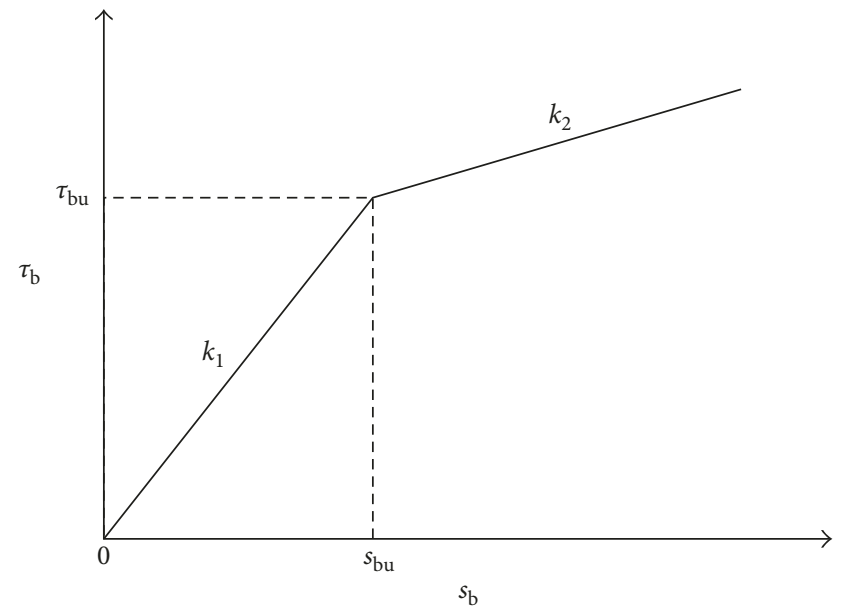

FIgURE 3: Pile top resistance-displacement curve.

where $\Delta P_{\mathrm{t}}$ is the pile top load increment, $\Delta S_{\mathrm{t}}$ is the pile top settlement increase caused by the pile top load increase, and $L$ is the pile length. The other symbols remain the same.

\section{Energy Balance Equation of Composite Foundation System}

3.1. Basic Assumptions. After the soil is subjected to load in the reinforced area, the soil particles are compressed 
and slipped to the equilibrium state, without considering the shear deformation of soil around the pile; ultimately, the soil surface is flat. Regardless of the interaction between the units, the compression of the analysis unit can be considered the compression of the composite foundation.

When analysing a typical unit, the following is supposed:

(1) Without considering the impact that lateral deformation of the pile has on the settlement, the pile skin friction is exerted before that of the pile bottom under the external load.

(2) The soil around the pile is isotropic homogeneous material, adopting a modified Cam-clay model. The soil surface is flat initially and after loading.

(3) The selected analysis unit is the central part of the foundation, and the soil is subjected to uniaxial compression consolidation without lateral displacement.

3.2. Pile Shaft Energy Equation. The total potential energy increment of the pile shaft in the foundation can be divided into two parts: the pile deformation energy $W_{\mathrm{u}}$ and the potential energy increment $W_{\mathrm{gp}}$ caused by the settlement, namely,

$$
\begin{aligned}
W_{\mathrm{u}} & =\int_{0}^{L} \frac{A_{\mathrm{p}}}{2} \sigma_{\mathrm{z}} \varepsilon_{\mathrm{z}} d z, \\
W_{\mathrm{gp}} & =-m_{\mathrm{z}} g\left(\int_{\mathrm{z}}^{L} \varepsilon_{\mathrm{z}} d_{\mathrm{z}}+s_{\mathrm{b}}\right) .
\end{aligned}
$$

In (7), $\sigma_{z}$ is the pile stress, $\varepsilon_{z}$ is the pile strain, $m_{z}$ is the pile mass at $\mathrm{z}$, and $g$ is the gravitational acceleration. In general, the stress in the design is half of the maximum stress, so it represents the rising section in the stress and strain curve, and the pile stress can be expressed as follows:

$$
\sigma_{\mathrm{z}}=\frac{q_{\mathrm{u}}}{\varepsilon_{\mathrm{u}}^{2}}\left(\varepsilon_{\mathrm{u}}-\varepsilon_{\mathrm{z}}\right) \varepsilon_{\mathrm{z}},
$$

where $q_{\mathrm{u}}$ is the unconfined limit strength and $\varepsilon_{\mathrm{u}}$ is the strain value corresponding to the ultimate strength.

External force potential consists of work by the load in the pile top $W_{\mathrm{p}}$ and work by the pile bottom resistance $W_{\mathrm{b}}$ :

$$
\begin{aligned}
& W_{\mathrm{p}}=p_{\mathrm{p}} s_{\mathrm{p} 0}, \\
& W_{\mathrm{b}}=-p_{\mathrm{b}} s_{\mathrm{b}},
\end{aligned}
$$

where $p_{\mathrm{b}}$ is pile bottom resistance.

3.3. Energy Equation of Soil. The soil around the pile and underlying stratum is calculated using the modified Camclay model. In 1968, Roscoe and Burland [34] further amended the Cam-clay model, believing that the yield surface trajectory of the Cam-clay model should be elliptical, with the following energy equation:

$$
\begin{aligned}
\mathrm{d} E & =\mathrm{d} W^{\mathrm{e}}+\mathrm{d} W^{\mathrm{p}}, \\
\mathrm{d} W^{\mathrm{e}} & =p d \varepsilon_{\mathrm{p}}^{\mathrm{e}}+q d \varepsilon_{\mathrm{q}}^{\mathrm{e}} \\
\mathrm{d} W^{\mathrm{p}} & =p \sqrt{\left(d \varepsilon_{\mathrm{p}}^{\mathrm{p}}\right)^{2}+M^{2}\left(d \varepsilon_{\mathrm{q}}^{\mathrm{p}}\right)^{2}},
\end{aligned}
$$

where $p$ is the mean effective stress, $q$ is the deviator stress, $d \varepsilon_{\mathrm{p}}^{\mathrm{e}}$ is the elastic volumetric strain increment, and $d \varepsilon_{\mathrm{q}}^{\mathrm{e}}$ is the elastic deviator strain increment. Assuming that all shear deformation is irreversible, then

$$
\begin{aligned}
d \varepsilon_{\mathrm{q}}^{\mathrm{e}} & =0, \\
\mathrm{~d} W^{\mathrm{e}} & =p d \varepsilon_{\mathrm{p}}^{\mathrm{e}}=\frac{\kappa}{1+e} d_{\mathrm{p}},
\end{aligned}
$$

where $e$ is the void ratio of the soil, $\kappa$ is the gradient of unloading or swelling line of structured clay, $d \varepsilon_{\mathrm{p}}^{\mathrm{p}}$ is the plastic volumetric strain increment, and $d \varepsilon_{\mathrm{p}}^{\mathrm{p}}$ is the plastic deviator strain increment. The incremental stress-strain of the modified Cam-clay model is

$$
\begin{aligned}
& d \varepsilon_{\mathrm{p}}^{\mathrm{p}}=\frac{\lambda-\kappa}{1+e}\left[\frac{1}{M^{2}+(q / p)^{2}} \times 2\left(\frac{q}{p}\right) d\left(\frac{q}{p}\right)+\frac{d p}{p}\right], \\
& d \varepsilon_{\mathrm{q}}^{\mathrm{p}}=\frac{\lambda-\kappa}{1+e}\left[\frac{2(q / p)}{M^{2}-(q / p)^{2}}\right]\left[\frac{2(q / p) d(q / p)}{M^{2}+(q / p)^{2}}+\frac{d p}{p}\right],
\end{aligned}
$$

where $\lambda$ is the gradient of isotropic compression line of destructured clay. The shape of the yam of the modified Cam-clay model is elliptical and its yield criterion is

$$
\frac{p}{p_{0}}-\frac{M^{2}}{M^{2}+(q / p)^{2}}=0
$$

where $M$ is the gradient of critical state line in the $q-p$ plane.

Since the selected element does not consider lateral deformation, the potential energy increment $W_{\mathrm{gs}}$ caused by soil subsidence is

$$
W_{\mathrm{gs}}=-m_{\mathrm{s}} g \int_{\mathrm{z}}^{L}\left(d \varepsilon_{\mathrm{p}}^{\mathrm{e}}+d \varepsilon_{\mathrm{p}}^{\mathrm{p}}\right) d_{\mathrm{z}}
$$

where $m_{\mathrm{s}}$ is the soil quality at $z$.

The external force potential is worked by $W_{\mathrm{s}}$ mainly for the soil surface:

$$
W_{\mathrm{s}}=p_{\mathrm{s}} s_{\mathrm{s} 0}
$$

\section{Calculation Process}

The total potential energy $\Pi$ of the composite foundation under the external load $p$ is equal to the deformation energy $U$ of both the pile and soil and the external potential energy $V$, that is, $\Pi=U+V$. According to the principle of minimum potential energy, for $\delta \Pi=0$, the true displacement makes the total potential energy of the system take an extreme value in all allowable displacements $u, v$, and $w$ that satisfy the known geometric boundary conditions. In the actual calculation, the pile top load $p_{\mathrm{p}}$ and the load of soil between the pile $p_{s}$ are unknown. To search the level of the load, the 
minimum potential energy principle is used to calculate. That is, under the external load $p_{\mathrm{p}, k}$ and $p_{\mathrm{s}, k}(k=1,2,3, \ldots$, $n_{\text {pos }}$ ), the total potential energy for $\Pi_{k}$ is calculated by the iteration to find the total potential energy minimum in the possible $n_{\text {pos }}$, which is calculated by the real pile-soil load. The calculation steps are as follows:

(1) Load is divided into $n_{\text {gra }}$ numbers to load, and then $j$ is loaded $\left(j=1,2,3, \ldots, n_{\text {gra }}\right)$, the external load at the pile top is $j p_{\mathrm{p}, k} / n_{\mathrm{gra}}$, and the load of the soil surface is calculated as $j p_{\mathrm{s}, \mathrm{k}} / n_{\mathrm{gra}}$ according to (1).

(2) The piles and soil around the piles are divided into $n_{\text {str }}$ layers, and the thickness and unit weight of the pile-soil are calculated.

(3) The layer $i\left(i=1,2,3, \ldots, n_{\text {str }}\right)$ is selected for pile calculation, $z=\left(i l / n_{\text {str }}\right)$, the unit body $i$ is loaded externally by $j p_{\mathrm{p}, k} / n_{\text {gra }}\left(\sigma_{0}\right)$; the corresponding pile stress is, $\sigma_{i}=\sigma_{i-1}+m_{\mathrm{z}} g-\tau_{i} \pi d\left(\sum_{i}^{n_{\text {str }}} \varepsilon_{\mathrm{z}}\left(l / n_{\mathrm{str}}\right)+\right.$ $\left.s_{\mathrm{b}}-\sum_{i}^{n_{\mathrm{str}}}\left(d \varepsilon_{\mathrm{p}, i}^{\mathrm{e}}+d \varepsilon_{\mathrm{p}, i}^{\mathrm{p}}\right)\left(l / n_{\mathrm{str}}\right)\right)$.

(4) The deformation energy and settlement potential of the pile are calculated according to (7) and (8), respectively.

(5) The soil around the pile calculation, unit body $i$, is subjected to the external load increment $j p_{\mathrm{s}, k} / n_{\text {gra }}$ $\left(\sigma_{\mathrm{s}, 0}\right)$, soil stress is $\sigma_{\mathrm{s}, i}=\sigma_{\mathrm{s}, i-1}+m_{\mathrm{s}} g$, and then $p$ and $q$ are calculated; (16) is used to determine whether it yields. If not, (14) is used to calculate the energy; otherwise, (11)-(13) are adopted. Its strain should be accumulated in the calculation of the soil.

(6) The $j$-level load and soil around the pile potential can be calculated according to (17); the total potential energy of soil is its cumulative value.

(7) Repeat steps (1) to (6), and $j$ is selected from 1 to $n_{\text {gra }}$

(8) The total potential energy of the pile and soil system $\Pi, \Pi=W_{\mathrm{u}}+W_{\mathrm{gp}}-W_{\mathrm{p}}-W_{\mathrm{b}}+\Sigma \mathrm{d} E+\sum W_{\mathrm{gs}}-W_{\mathrm{s}}$;

(9) Repeat steps (1) to (8), and $k$ is selected from 1 to $n_{\text {pro. }}$

(10) Within a reasonable range, when $\Pi_{k}$ is the minimum, then $p_{\mathrm{p}, k}$ and $p_{\mathrm{s}, k}$ stand for the actual load value of the pile and soil, and the corresponding stress is that of the reinforcement area.

\section{Examples and Discussion}

5.1. Example 1. To study the accuracy of the calculation, the model test of the soil-cement pile composite foundation with a lateral constraint was conducted in a trough with dimensions of $6000 \mathrm{~mm} \times 3000 \mathrm{~mm} \times 4000 \mathrm{~mm}$ (length $\times$ width $\times$ height) in the laboratory, and the geometric similarity ratio of the piles was $1: 6$. After the filling, the top of the filling soil was covered with thin film to retain moisture, which formed the pile after deposit for 28 days. The cementsoil mixture that was made for the cement-soil pile was mixed clay with cement. The same clay was used in the soilcement mixture and filling soil, for which the air drying, crushing, screening, and measuring of the moisture content

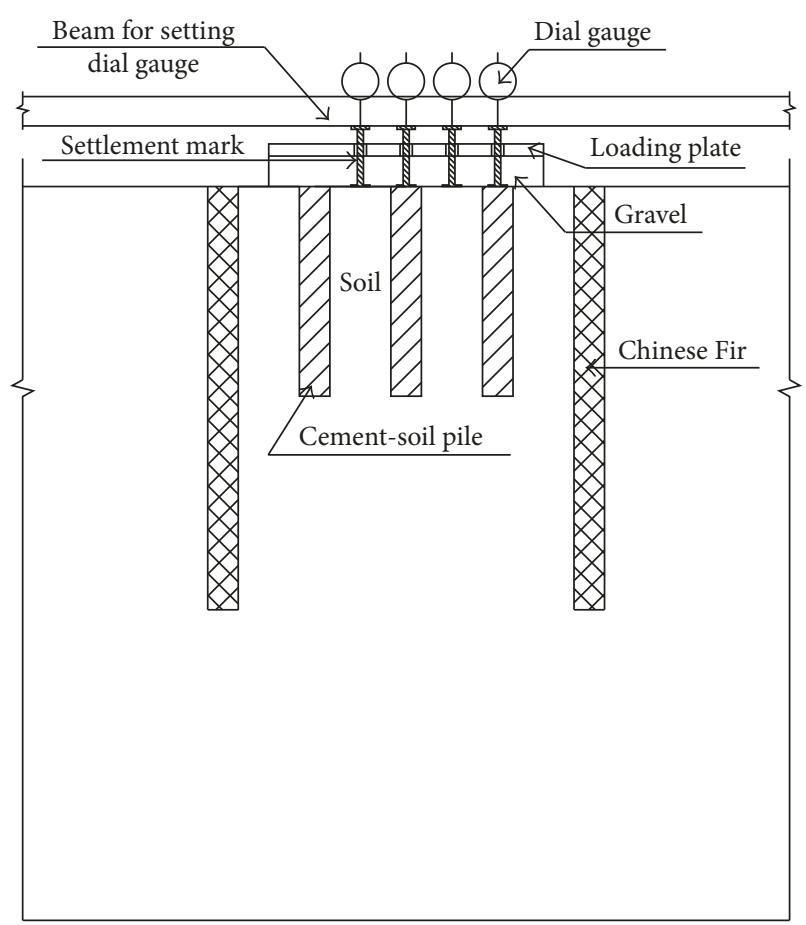

Figure 4: Test arrangement.

of the soil are similar to those of the former, which was only sieved with a sieve of $1 \mathrm{~mm}$ mesh to accelerate the interaction with cement and avoid a great difference of cement-soil mixture. Ordinary Portland cement was used, of which the strength grade was 32.5 according to China General Cement Code (GB175-2007), and the dosage was $\alpha_{\mathrm{w}}=10 \%$. The moisture of the mixture achieved the optimal $19.2 \%$. The cement-soil pile was made by ramming the cement-soil mixture into a borehole in layers, with a compaction factor of 0.9. Chinese Fir was used in the pile with the constraint parameters shown in Figure 4. The central three piles of each group of piles served as test piles, and the pile spacing was three times the pile diameter. Pile bottom stress was tested by the earth pressure box, and pile shaft stress tests adopted a PVC pipe paste strain gauge; its specific process is shown in [35].

The load test was carried out after 29 days of forming the pile. The load plate size (steel plate) for loading was $707 \mathrm{~mm} \times 707 \mathrm{~mm} \times 20 \mathrm{~mm}$. The test adopted the fast maintenance load method. Each load is $8 \mathrm{kPa}$ and the total load is $56 \mathrm{kPa}$ in the test, as shown in Figures 4 and 5.

The soil was selected to carry out the experiment. The calculation parameters of the soil were obtained, as shown in Table 1.

In this paper, the Maple software is used to compute the above calculation program, which divided the pile and soil around the pile into 120 elements. The load is divided into 100 loadings. The $0.1 \mathrm{~m}$ gravel cushion without restraint diffuses the upper load. According to the Technical Code for Ground Treatment of Buildings of China (JGJ-2012), the load at the bottom of cushion is calculated to be $46.37 \mathrm{kPa}$. The pile-soil stress under the last load was calculated. It is calculated that when the pile top load reaches $0.837 \mathrm{kN}$, the 


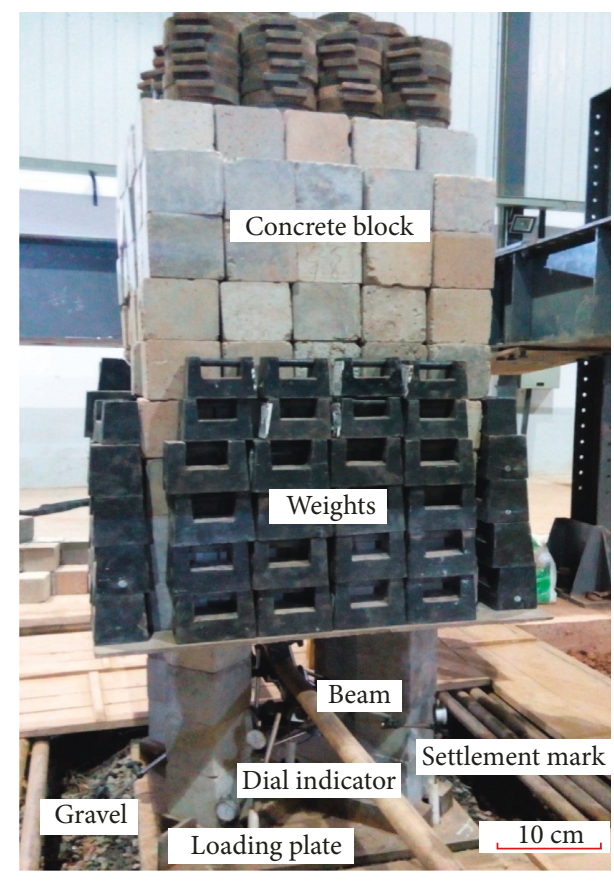

Figure 5: Picture of the pile group with load.

TABle 1: Physical mechanical index of soils.

\begin{tabular}{lcccc}
\hline$\gamma\left(\mathrm{kN} \cdot \mathrm{m}^{-3}\right)$ & $\lambda$ & $\kappa$ & $\mu$ & $M$ \\
\hline 18.1 & 0.036 & 0.007 & 0.40 & 0.742 \\
\hline
\end{tabular}

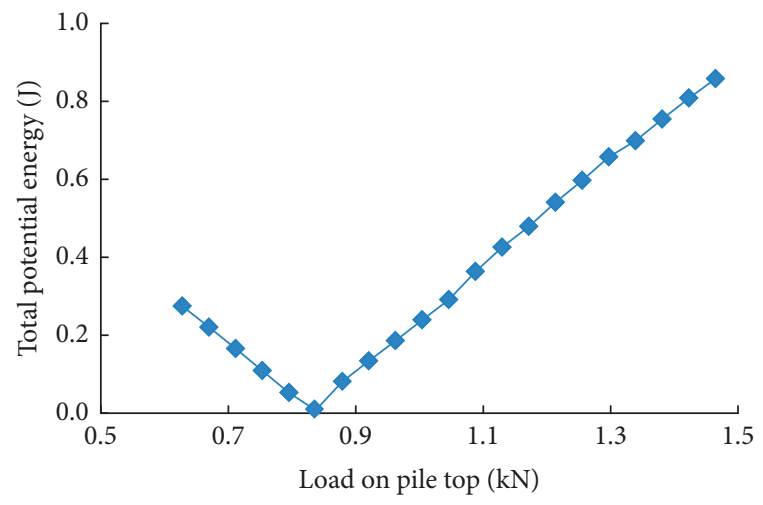

FIGURE 6: Energy with load on pile top.

total potential energy of the system reaches its minimum (Figure 6), and its stress is $106.6 \mathrm{kPa}$.

The calculation results of the pile-soil stress are shown in Table 2.

As seen from Table 2, the calculated value is slightly larger than the measured value, which occurred because the cushion diffused the upper load in the test and the load on the centre pile was less than the upper load. As seen from Figure 7 , the calculated pile shaft stress shows a similar curve to that of the measured value, and the maximum stress of the pile lies at 0.3 times the pile length from the pile top. The calculated values are well close to the experimental values above the maximum stress of the pile, but the
TABLE 2: Comparison between calculated and measured stress.

\begin{tabular}{lccc}
\hline & $\begin{array}{c}\text { Pile top } \\
\text { stress }(\mathrm{kPa})\end{array}$ & $\begin{array}{c}\text { Soil } \\
\text { stress }(\mathrm{kPa})\end{array}$ & $\begin{array}{c}\text { Pile-soil } \\
\text { stress ratio }\end{array}$ \\
\hline Measured & 110.5 & 42.5 & 2.60 \\
Calculated & 106.6 & 40.6 & 2.62 \\
\hline
\end{tabular}

Pile shaft stress is shown in Figure 7.

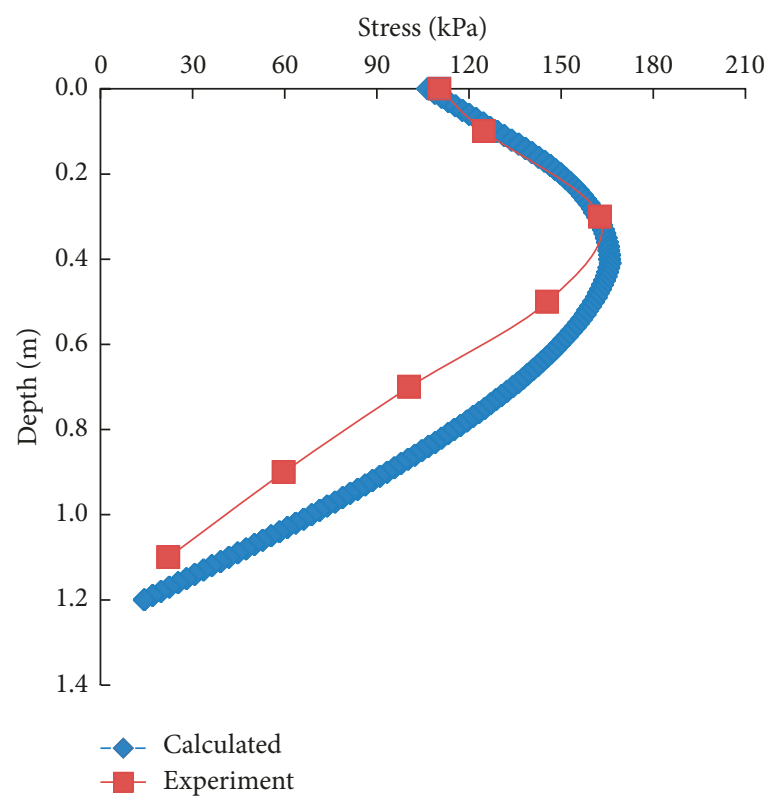

Figure 7: Pile shaft stress along with depth.

deviations exist down the maximum stress of the pile. It is analysed that the main reason lies in the compaction on the soil around the pile during pile forming, which increased the side friction of the soil and reduced the pile stress. The maximum stress is 1.56 times the pile stress of the pile top, which is close to the measured value of 1.47 . The results show that the calculation method proposed in this paper is reliable.

5.2. Example 2. To further verify the reliability of the calculation method, the case of a field test is calculated. A clay with thickness of approximately $16.0 \mathrm{~m}$ was developed in the shallow foundation of a highway test section. The cementsoil mixing pile with $\varphi 0.5 \mathrm{~m} \times 8.0 \mathrm{~m}$ and $\varphi 0.5 \mathrm{~m} \times 17.0 \mathrm{~m}$ is designed to carry out reinforcement treatment for the soft foundation. The mixing pile spacing was $1.4 \mathrm{~m}$ and was arranged as a plum blossom. The final embankment height was $4.9 \mathrm{~m}$, which is equivalent to the embankment load of $96.0 \mathrm{kPa}$. In load testing of the test section, a circular load plate with a diameter of $2.73 \mathrm{~m}$ was used to carry out the load test of the three-pile composite foundation. Six vibrating earth pressure boxes (three on the pile top and three in the pile) were arranged to observe the stress distribution between the centre pile and soil around the pile in the composite foundation and the relationship with the load level. At the end of the test, the pile-soil stress ratio was 2.61. 
TABle 3: Physical mechanical index of soils.

\begin{tabular}{lcccc}
\hline$\gamma\left(\mathrm{kN} \cdot \mathrm{m}^{-3}\right)$ & $\lambda$ & $\kappa$ & $\mu$ & $M$ \\
\hline 18.2 & 0.045 & 0.01 & 0.40 & 0.608 \\
\hline
\end{tabular}

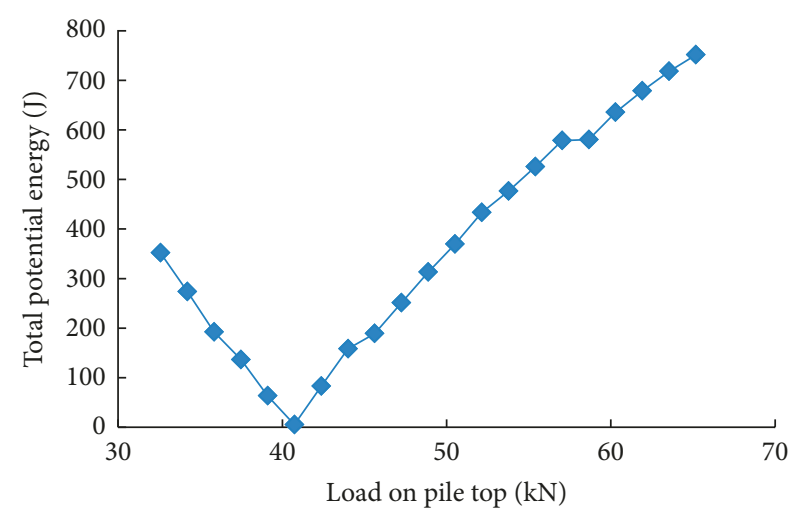

FIGURE 8: Energy with load on pile top.

TABLE 4: Comparison between calculated and measured stress ratio.

\begin{tabular}{lccc}
\hline & $\begin{array}{c}\text { Pile top } \\
\text { stress }(\mathrm{kPa})\end{array}$ & $\begin{array}{c}\text { Soil } \\
\text { stress }(\mathrm{kPa})\end{array}$ & $\begin{array}{c}\text { Pile-soil } \\
\text { stress ratio }\end{array}$ \\
\hline Measured & & & 2.61 \\
Calculated & 207.3 & 81.4 & 2.55 \\
\hline
\end{tabular}

According to [36] and experience, the calculation parameters were selected as shown in Table 3.

In this paper, the Maple software is used to compute the above calculation program, which divides the pile and soil around the pile into 80 elements, and the load is divided into 100 loadings. The pile-soil stress under the last load is calculated. It is calculated that when the pile top load is $40.7 \mathrm{kN}$, the total potential energy of the system reaches its minimum, and its stress is $207.3 \mathrm{kPa}$, as shown in Figure 8 .

The calculation results of the pile-soil stress are shown in Figure 8. As shown in from Table 4, the calculated value is close to the measured value. The two cases show that the calculated results in the paper are in agreement with the measured values and therefore the calculation method is reliable.

5.3. Discussion. It is generally believed that the parameters which exert great influence on the results are as follows: $M, \lambda$, and $\kappa$ in the correction of the parameters for the modified Cam-clay model. This paper analyses the sensitivity of the three parameters. The results of the study are shown in Figure 9. The horizontal line represents the increase and decrease of parameters, while the vertical line indicates the stress ratio of pile-soil.

As can be seen from Figure 9, the stress ratio first decreases and then increases with the increase of $M$. When $M$ decreases by $20 \%$, the stress ratio increases from 2.69 to 4.30. When $M$ increases by $20 \%$, the stress ratio increases from 2.69 to 3.60. When $M$ decreases, which means that the soil is to deteriorate under the lower stress, the shear

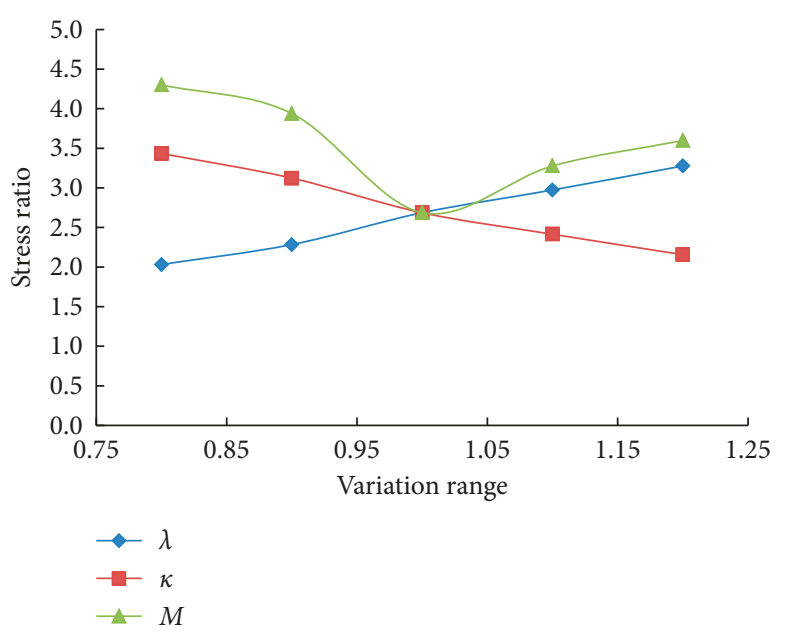

FIGURE 9: Stress ratio-parameter variation.

strength of the soil decreases; correspondingly, the pile undergoes great load, and therefore the stress ratio of the pilesoil increases. When $M$ increases, the increase of $\mathrm{q}$ will improve the compressibility of the soil, so that the differential settlement of pile-soil will increase, the load will be transferred to the pile around, which undergoes greater load. Generally speaking, when $M$ increases or decreases to the same extent, the decrease of soil bearing capacity is more than the load transfer, so the stress ratio of pile-soil when $M$ decreases by $20 \%$ is greater than that when $M$ increases by $20 \%$.

The stress ratio of pile-soil shows approximate linear increase with the increase of $\lambda$. The parameter $\lambda$ indicating compressibility means that the soil has more porosity ratio and compression when $\lambda$ increases. The differential settlement of the pile-soil increases with the increase of $\lambda$, and the load will be transferred to the pile around; hence, the stress ratio of the pile-soil increases. Zhang [37] shows that the horizontal displacement increases when $\lambda$ increases, while the horizontal displacement is proportionate to the vertical displacement. It is safe to say that the settlement increases with the increase of $\lambda$, which is similar to the results in this paper.

The stress ratio of pile-soil shows approximate linear decrease with the increase of $\kappa$. The main reason is that when $\kappa$ increases, the soil resilience will increase, signifying small compression of the soil and the slight settlement difference of the pile-soil; therefore, the soil shares more load, and the stress ratio of the pile-soil tends to be smaller. When $\kappa$ increased from 0.8 to $1.2 \kappa$, the stress ratio of pile-soil changed from 3.28 to 2.03 .

\section{Conclusions}

(1) The modified Cam-clay model is used to establish the equation of the deformation energy and potential energy of soil around the pile in the composite foundation. On the basis of the nonlinear stressstrain relationship of the cement-soil pile, the expression of deformation energy and potential energy of the pile is obtained. 
(2) According to the principle of minimum potential energy, the total energy equation of the composite foundation system is established and programmed. The verification of two cases shows that the calculated values are in good agreement with the measured values; therefore, that the calculation method is reliable.

(3) The parameters of the modified Cam-clay model exert great influence on the calculation results. Therefore, the accuracy of the parameters determines the reliability of the stress calculation. It is suggested that the representative core-drilling holes be tested and the number of tests should be increased.

\section{Data Availability}

The data used to support the findings of this study are available from the corresponding author upon request.

\section{Conflicts of Interest}

The authors declare no conflicts of interest.

\section{Acknowledgments}

The experiment was carried out at Hunan University of Technology. The authors gratefully acknowledge their invaluable cooperation in our test. In particular, the authors would like to thank Professor Jie He and Professor Jie Liu for their guidance.

\section{References}

[1] F. Liu, B. Fan, and T. Zhang, "Analysis on subgrade treatment of Shenyang-Dandong passenger dedicated line with flexible piles," Bridge and Tunnel Construction and Machinery, vol. 30, no. 11, pp. 104-106, 2013.

[2] C. Zeng, Y. Cheng, D. Wu et al., "Comparison of different foundation treatment effects on thick sand overlying thick silt foundation of high speed railway," China Railway Science, vol. 35, no. 4, pp. 1-8, 2014.

[3] Z. Gou, "Discussion on load pile-soil sharing of cement-soil mixing pile composite foundation," in Proceedings of the Third National Symposium on Foundation Treatment, pp. 179-182, Qinhuangdao, China, June 1992.

[4] J. Chen, F. Ren, and S. Jiang, "Stress ratio analysis of pile and soil in cement-stabilized soil pile foundation," Soil Mechanics and Foundation Engineering, vol. 7, no. 2, pp. 36-40, 1993.

[5] V. Baumann and G. Bauer, "The performance of foundations on various soils stabilized by the vibro-compaction method," Canadian Geotechnical Journal, vol. 11, no. 4, pp. 509-530, 1974.

[6] H. Poulos and E. Davis, Pile Foundation Analysis and Design, John Wiley \& Sons, Hoboken, NJ, USA, 1st edition, 1980.

[7] J. Duan, Numerical analysis of flexible pile composite foundation, $\mathrm{PhD}$ dissertation, Zhejiang University, Hangzhou, China, 1993.

[8] M. Kitazume and M. Terashi, "Design of improved ground by the deep mixing method," in The Deep Mixing Method, pp. 303-305, CRC Press, Leiden, Netherlands, 1st edition, 2013.
[9] X. Song, W. Song, and G. Su, "On pile-soil stress ratio of dry jet mixing pile (DJMP)," Journal of Shandong University: Engineering Science, vol. 33, no. 4, pp. 467-469, 2003.

[10] R. Ishikura, H. Ochiai, K. Omine et al., "Estimation of the settlement of improved ground with a combined technology of shallow stabilization and floating-type cement treated columns," Journal of Geotechnical Engineering, vol. 63, no. 4, pp. 1101-1112, 2007.

[11] R. Ishikura, N. Yasufuku, and M. J. Brown, "An estimation method for predicting final consolidation settlement of ground improved by floating soil cement columns," Soils and Foundations, vol. 56, no. 2, pp. 213-227, 2016.

[12] M. Alamgir, N. Miura, H. B. Poorooshasb et al., "Deformation analysis of soft ground reinforced by columnar inclusions," Computers and Geotechnics, vol. 18, no. 4, pp. 267-290, 1996.

[13] J. Liu and K. Zhang, "Load transfer law and deformation calculating of the composite found," China Journal of Highway and Transport, vol. 17, no. 1, pp. 20-23, 2004.

[14] W. Lv, J. Yu, and X. Gong, "Analytical method for pile composite ground under flexible foundation," Chinese Journal of Rock Mechanics and Engineering, vol. 29, no. 2, pp. 401-408, 2010.

[15] J. Yu, Z. Jing, X. Gong et al., "Working behaviors of composite ground under flexible foundation based on super-sub structure interaction," Chinese Journal of Geotechnical Engineering, vol. 32, no. 5, pp. 657-666, 2010.

[16] J. Yu, J. Li, W. Lv et al., "Behavior analysis of composite ground with flexible foundation using orthogonal test," Journal of Central South University, vol. 42, no. 11, pp. 3478-3485, 2011.

[17] R. Qin, Z. Chen, and P. Dong, "Analytical calculation on pilesoil stress ratio of cement-soil foundation," Rock and Soil Mechanics, vol. 22, no. 1, pp. 96-98, 2001.

[18] B. Huang and H. Huang, "Calculation of pile-soil stress ratio of composite foundation," Engineering Design and Construction, vol. 37, no. 3, pp. 1-4, 2005.

[19] J. Zheng and H. Huang, "Analytical solution of pile-soil stress ratio of soil-cement pile composite foundation," Rock and Soil Mechanics, vol. 26, no. 9, pp. 1432-1436, 2005.

[20] B. K. Low, S. K. Tang, and V. Choa, "Arching in piled embankments," Journal of Geotechnical Engineering,vol. 120, no. 11, pp. 1917-1938, 1994.

[21] Z. Hu, "Behaviors analysis of composite ground under flexible foundation," M.S. thesis, Hunan University, Changsha,China, 2012.

[22] L. Zhou, M. Wang, D. Zhang et al., "Study of the soil arching effect and the pile-soil stress ratio of composite ground," China Civil Engineering Journal, vol. 44, no. 1, pp. 93-99, 2011.

[23] C. Zhao, Y. Li, and T. Qian, "Analytical calculation of pile-soil stress ratio of cement-soil mixed pile composite foundation," Journal of Central South University, vol. 43, no. 6, pp. 23902395, 2012.

[24] M. Yang, Y. Yao, and M. Zhao, "Pile-net composite foundation bearing mechanism and the method to calculate the pile-soil stress ratio in high embankment," Journal of Hunan University, vol. 42, no. 5, p. 180, 2015.

[25] M. Zhao, M. Liu, B. Ma et al., "Calculation of pile-soil stress ratio and settlement of pile-net composite foundation based on elastic foundation plate," Journal of Central South University, vol. 47, no. 6, pp. 2007-2014, 2016.

[26] W. Y. Shen, Y. K. Chow, and K. Y. Yong, "A variational approach for the analysis of pile group-pile cap interaction," Geotechnique, vol. 50, no. 4, pp. 349-357, 2010. 
[27] J. Zheng, J. Ou, N. Yuan et al., "A new way to calculate modulus of compressibility of composite foundation," Journal of Railway Engineering Society, vol. 20, no. 1, pp. 117-119, 2003.

[28] S. Liu, M. Zhao, and Z. Yan, "Numerical calculation of pile vertical load-settlement curve based on energy method," Journal of Highway and Transportation Research and Development, vol. 27, no. 8, pp. 22-26, 2010.

[29] Y. Yang, "Settlement calculation of pile foundations with elevated caps by energy method," M.S. thesis, Hunan University, Changsha, China, 2013.

[30] M. Zhao, Y. Yang, P. Yin et al., "Settlement calculation of pile foundations with elevated caps by energy method," Journal of Central South University, vol. 46, no. 2, pp. 670-675, 2015.

[31] W. Shen, Y. Chi, and E. Song, "Settlement calculation of composite ground with rigid piles including pile-soil-cushion interaction," Engineering Mechanics, vol. 20, no. 2, pp. 36-42, 2003.

[32] Q. Zhang, S. Li, L. Li et al., "Simplified method for settlement prediction of pile groups considering skin friction softening and end resistance hardening," Chinese Journal of Rock Mechanics and Engineering, vol. 32, no. 3, pp. 615-624, 2013.

[33] M. F. Randolph and C. P. Wroth, "An analysis of the vertical deformation of pile groups," Geotechnique, vol. 29, no. 4, pp. $423-439,1979$.

[34] K. H. Roscoe and J. B. Burland, "On the generalized stressstrain behavior of 'wet' clay," in Engineering Plasticity, pp. 535-609, Cambridge University Press, London, UK, 1968.

[35] Y. Wu, J. Liu, and J. He, "Experiment and study on the stress testing of cement-soil piles," Journal of Hunan University of Technology, vol. 26, no. 1, pp. 23-26, 2012.

[36] G. Li, Advanced Soil Mechanics, Tsinghua University Press, Beijing, China, 1st edition, 2004.

[37] Y. Zhang, "Effects of parameters of modified Cambridge model on computed results," Rock and Soil Mechanics, vol. 27, no. 3, pp. 441-444, 2006. 


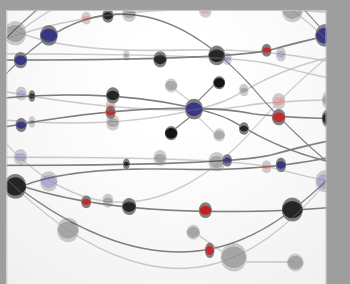

The Scientific World Journal
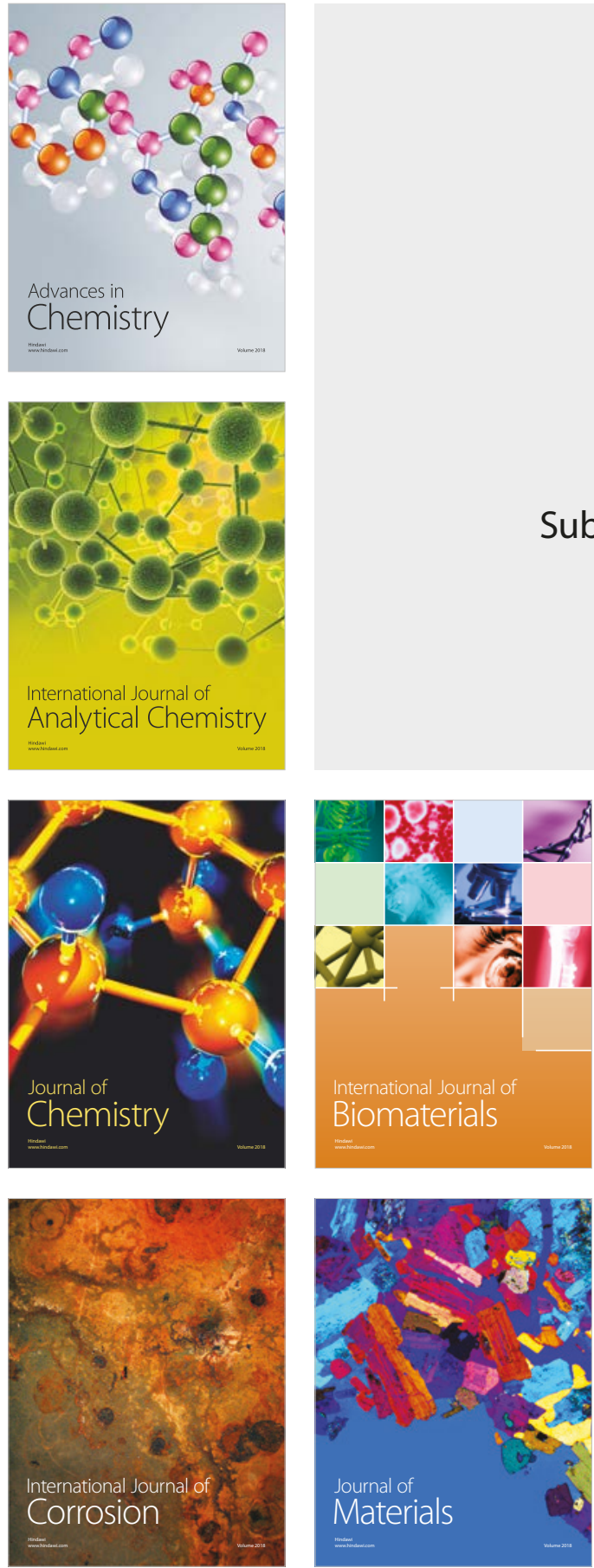

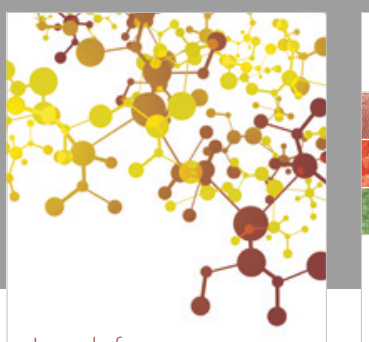

Journal of

Applied Chemistry
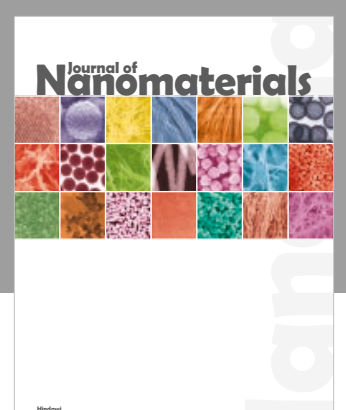

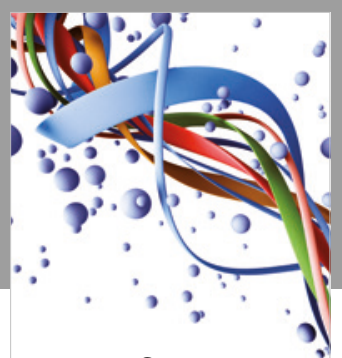

Scientifica

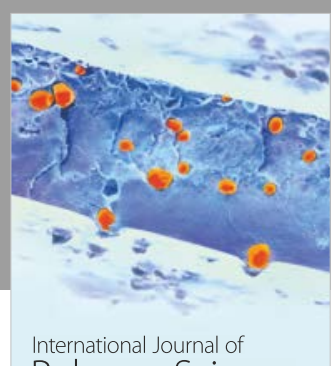

Polymer Science

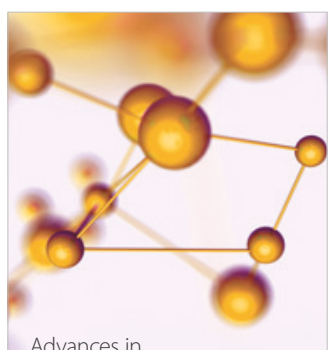

Physical Chemistry
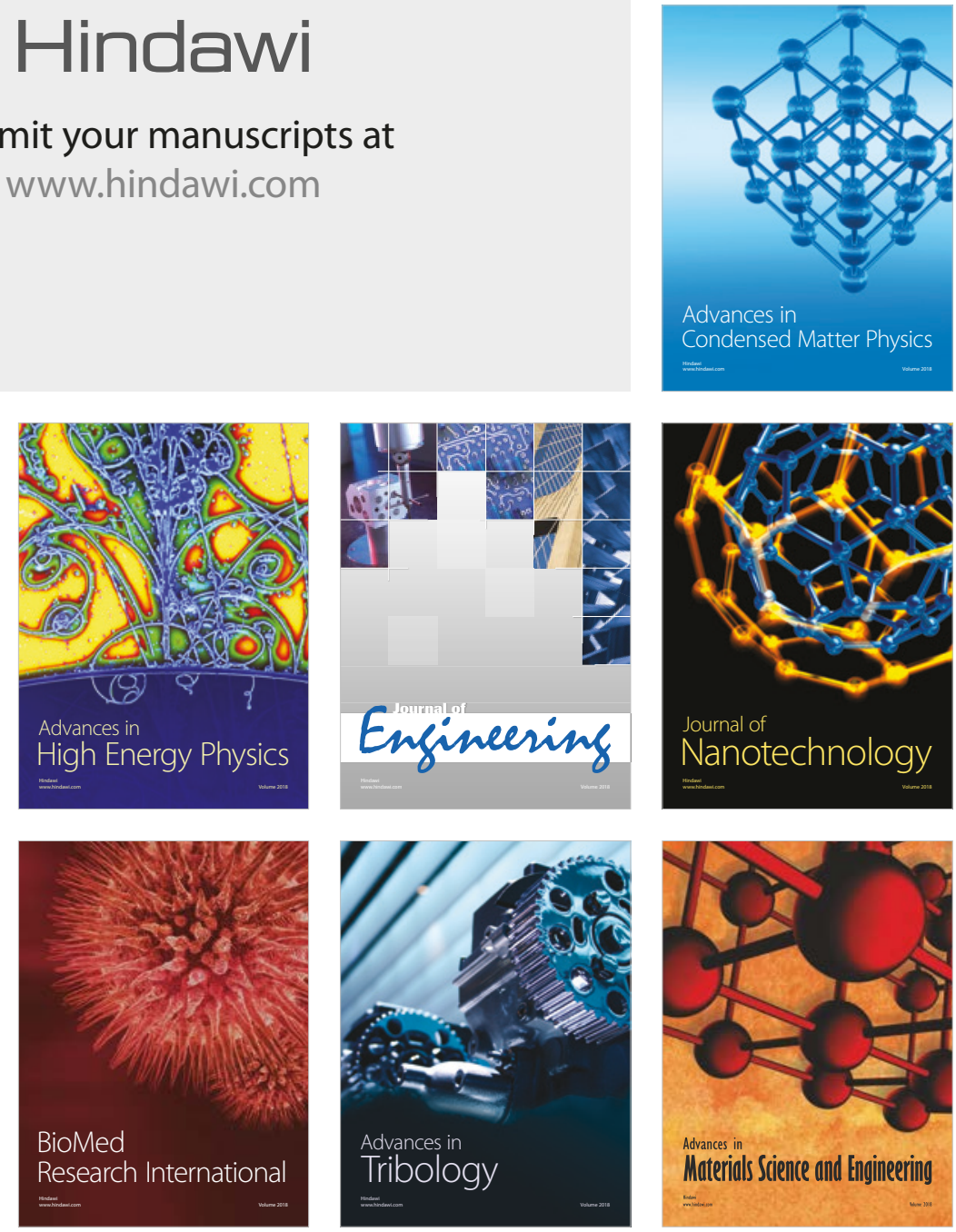